Although Case 1 is of blood group $O$ and a non-secretor, he has remained perfectly well since his incomplete vagotomy was completed two years ago. Case 2 also is blood group $O$ and a non-secretor. He had antral retention and a gastrojejunal ulcer, but has been symptom-free for three years and no ulcer has been found on $x$-ray examination.

These two cases may suggest that duodenal ulceration is more likely to occur in patients of blood group $O$ who are nonsecretors, but they did not suggest that any thing more than complete vagotomy and good antral drainage is ever required to cure duodenal ulceration.

Cases 3 and 4 are both group $A$. Case 5 is group $O$ and a non-secretor. She has never had symptoms of recurrent ulceration, nor has there ever been $x$-ray evidence of it.

If, as we believe, recurrent ulceration after vagotomy and simple drainage occurs only in the presence of incomplete nerve section or an antrum badly drained by technical error, then the operation may be used in all cases and there is never need to estimate gastric acids or to consider the blood group and bloodgroup-antigen factor. It is true that acid studies may be helpful in the diagnosis of the Zollinger-Ellison syndrome, but if the pancreas is routinely palpated at operation, even here they are unnecessary.

Pyloroplasty, for several reasons, seems preferable to gastrojejunostomy. In the early post-operative period it is entirely free from loop obstructions and bilious vomiting, and later bilious regurgitation and dumping are rare. This is certainly not so after gastrojejunostomy.

If gastrojejunostomy is performed proximal to a stenosed pylorus or duodenum, antral retention may cause gastrojejunal ulceration. If pyloroplasty is used the incision should be long $(8 \mathrm{~cm}$.) and should divide completely any duodenal narrowing. It is closed preferably with a single layer of interrupted thread sutures ; then the stoma is large and antral emptying should be satisfactory.

\section{Summary}

In 200 patients in whom the electrical stimulation test has been used at the time of vagotomy and simple drainage for duodenal ulcer only one patient has come to further operation for recurrent ulceration. In this case incomplete nerve section was found. In another, gastrojejunal ulceration occurred after vagotomy and gastrojejunostomy, and was apparently due to antral retention. It healed spontaneously and has remained so. In two other patients gastric bleeding with anaemia had apparently been caused by a gastritis in an antrum retentioned by a badly-made drainage operation.

This interim report suggests that there is never need to excise the antrum if vagotomy and simple drainage is properly performed.

\section{REPERBNCES}

Austen, W. G., and Edwards, H. C. (1961). Gut, 2, 158.

Bancroft, F. W. (1932). Amer. F. Surg., 16, 223.

Bruce, J., Card, W. I., Marks, I. N., and Sircus, W. (1959). F. roy. Coll. Surg. Edinb., 4, 85

Burge, H. (1958). Eleventh Alexander Simpson Smith Memorial Lecture, West London Hospital Medical School, London.

and Clark, P. A. (1960). Gastroenterology, 39, 572

- and Vane, J. R. (1598). Brit. med. 7. 1, 615

Carman, R. D. (1917). Amer. f. Roentgenol., 4, 552.

Dragstedt, L. R. (1948). Gastroenterology, 11, 468.

Edwards, L. W., Classen, K. L., and Sawyers, J. L. (1960). Ann. Surg., 151,827 .

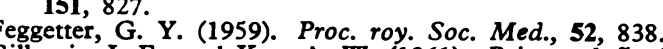

Gillespie, I. E., and Kay, A. W. (1961). Brit. med. f., 1, 1557

Harkins, H. N., Jesseph, J. E., Stevenson, J. K., and Nyhus, L. M. (1960). Arch. Surg., 80, 743.

Hoerr, S. O. (1959). Cleveland Clin. Quart., 26, 170.

Holt, R. L. (1959). Proc. roy. Soc. Med., 52, 837

Kay, A. W. (1964). Brit. med. ₹., 1, 754.

Rigler, S. P. (1959). In The Physiology and Treatment of Peptic Ulcer, edited by J. G. Allen, p. 176. Univ. of Chicago Press, Chicago.

Smithwick, R. H., Harrower, H. W., and Farmer, D. A. (1961). Amer. 7. Surg., 101, 325.

Stempien, S. J., Dagradi, A. E., and Seifer, H. W. (1959). World Congress of Gastroenterology, 2, 1026. Williams and Wilkins, Baltimore.

Weinberg, J. A., Stempien, S. J., Movius, H. J., and Dagradi, A. B. (1956). Amer. F. Surg., 92, 202.

\title{
Infections by Organisms of Psittacosis/Lymphogranuloma Venereum Group in the West of Scotland
}

\author{
N. R. GRIST,* M.B., B.SC., F.R.C.P.ED., M.C.PATH. ; C. MCLEAN, † F.I.M.L.T.
}

Brit. med. F., 1964, 2, 21-25

Psittacosis, ornithosis, lymphogranuloma venereum (L.G.V.), trachoma, and inclusion conjunctivitis are well-recognized human diseases caused by viruses of a group which is widespread in nature. These organisms parasitize warm-blooded animals and birds, sometimes causing acute pneumonic illness, enteritis of calves, abortion of ewes, or encephalomyelitis of cattle. Characteristically, they may cause in their usual hosts chronic or latent infections. Thus in man trachoma and L.G.V. are chronic infections with granulomatous and fibrotic reactions, while chronic symptomless infections of the female genital tract by venereal-transmitted virus provide the infectious reservoir of inclusion conjunctivitis. Chronic pulmonary infection of man with psittacosis virus has also been described (Meyer and Eddie, 1951).

The causal organisms of this group are obligatory parasites of specific cells and resemble viruses in the intimacy of integration with their host cells. Unlike typical viruses, they are susceptible to several antibiotics and sulphonamides, and are large enough to be seen through the optical microscope during most of their complex developmental cycle. These characteristic morphological appearances are utilized in the routine microscopical diagnosis of trachoma and inclusion blennorrhoea. A common thermostable polysaccharide antigen is shared by viruses of the psittacosis-L.G.V. group. Complement-fixing (C.F.) antibodies to this antigen appear during infection by psittacosis and L.G.V. viruses, and detection of these antibodies is the basis of routine serological diagnosis of such infections.

The following report describes human infections diagnosed by the use of this serological test in Glasgow from 1950 to 1963 inclusive, together with a limited survey of non-human reservoirs of infection in this area.

\footnotetext{
* Reader in Viral Epidemiology, University of Glasgow.

tChief Technician, Regional Virus Laboratory, Ruchill Hoopiral, Glasgow.
} 


\section{Materials and Methods}

In view of the low frequency $(<1 \%)$ of positive results of serological tests of over 800 unselected patients admitted to the pneumonia wards of Knightswood and Ruchill Hospitals, Glasgow, during 1950-2 (Grist, 1954), tests were subsequently restricted to cases of suspected virus pneumonia, undiagnosed fever, venereal syndromes, or other diseases where infection with a virus of the psittacosis group seemed possible. This diagnostic facility has been extended to the whole Western Regional Hospitals Board area since 1953. Blood for serological tests, and specimens of liver, spleen, and kidney for attempted virus isolation, when available, were collected from birds associated with human infections. Such specimens were also taken for survey purposes from birds collected in Glasgow by public health officers and from several moribund or severely injured wild birds found in the city.

Virus isolation was attempted by preparation of $20 \%$ tissue suspensions containing $200 \mu \mathrm{g}$. of streptomycin per $\mathrm{ml}$. These were inoculated in $0.03-\mathrm{ml}$. amounts intracerebrally in four to six mice, and in up to $1-\mathrm{ml}$. amounts by the intraperitoneal route into another four mice. Sick mice of the first group were killed, and impression smears from their brain surface were examined microscopically after staining by Giemsa's and Macchiavello's methods : a positive diagnosis was based on the characteristic morphological appearances of intracellular virus, and was in some cases confirmed by subinoculation into the yolk-sacs of embryonated eggs and preparation of specific C.F. antigen. If the intracerebrally inoculated animals did not sicken within a fortnight the intraperitoneally inoculated mice were killed : extracts of their spleens were inoculated intracerebrally into further mice, which were observed and treated as already described. Only one of the four isolations (from a pigeon) was made by this passage technique.

Antigen for C.F. tests was made by boiling virus suspensions prepared by differential centrifugation of extracts of the yolk sacs of eggs infected with the virus of enzootic abortion of ewes (Stamp et al., 1950). Control antigen was prepared from uninfected eggs by the same method. Similar antigen prepared from psittacosis virus was provided by Dr. A. D. Macrae, of the Virus Reference Laboratory, London, for the preliminary survey of 1950-1. This thermostable antigen is group-specific in reaction, common to psittacosis, ornithosis, L.G.V., and other members of the group.

The C.F. test was carried out from 1950 to 1958 in tubes using saline as diluent, incubating $0.1 \mathrm{ml}$. each of antigen, serum dilution, and 2 M.H.D. complement at $37^{\circ}$ C. for one and a half hours before the addition of $0.2 \mathrm{ml}$. of $1 \%$ sensitized sheep cells. In 1958 the cold-overnight fixation method in plastic trays was adopted, with barbiturate-buffered calcium magnesium-saline as diluent, using $0.1-\mathrm{ml}$. volumes each of antigen, serum dilution, and 4 H.D. ${ }_{50}$ of complement, followed by the addition of $0.1 \mathrm{ml}$. of $2 \%$ sensitized cells. Sera gave approximately twofold higher titres by this second method. Avian sera which reacted negatively by this direct test were retested by the indirect C.F. method (Karrer et al., 1950). Except for some sera from cases of L.G.V., human sera were also tested with influenza soluble antigens, and in most cases with antigens of adenovirus and Coxiella burnetii.

\section{Results}

During the 14-year period a serological diagnosis of infection was made in 45 patients, 22 of them in the last four years. The diagnosis was based on the demonstration of fourfold or greater rising C.F. antibody titres in 12, of fourfold or greater falling titres in 5 whose initial titres ranged from 64 to 512 , and on static or single-serum titres of at least 64 (by the original method) or at least 128 (by the cold-overnight
C.F. method) in the remainder. No rising antibody titres were found in L.G.V., since by the time its symptoms necessitate medical attention infection has been established long enough for full antibody response. One case of pneumonia showed the transient false-positive serological reactions for syphilis which are sometimes encountered in infections with psittacosisgroup organisms (Allison and Dick, 1954). Another case of pneumonia (Case A) showed titres rising from $<8$ to 128 with both psittacosis-group and Q-fever antigen but not with heterologous control antigens, and was thought to have a dual infection.

The illnesses have been grouped under four headings: pneumonia (13 males, 11 females), non-specific fever (3 males, 2 females), L.G.V. (10 males), and other conditions (3 males, 3 females). Little information is available about the 10 cases of L.G.V., except that most of them were seamen whose infections were acquired in foreign ports. The other 35 cases are analysed in the Table by age and season of onset of illness.

Age and Season of Onset of 35 Infections (L.G.V. Excluded)

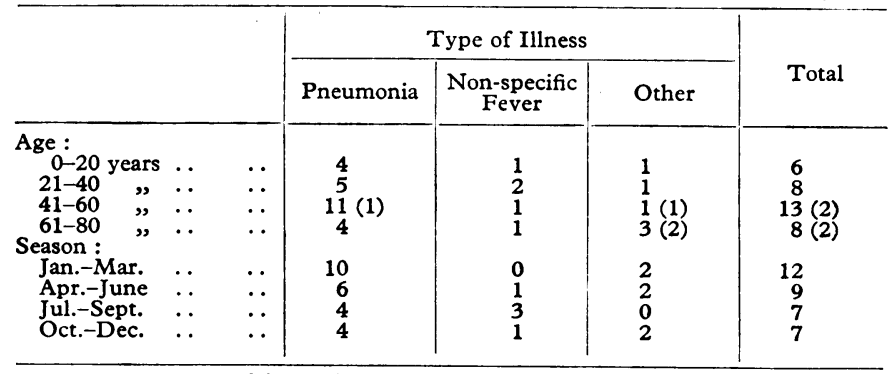

Figures in parentheses indicate deaths.

Ages ranged from 6 years (a boy with pneumonia) to 75 (Case B, a woman who died with bronchitis and heart failure). There was little seasonal variation except in pneumonia, which had a higher incidence in the first half, particularly in the first quarter of the year.

\section{Pneumonia}

The onset of illness in these 24 cases was sudden in nine, gradual in 10, and not recorded in five. Prominent early symptoms were fever, shivering, or rigors in eight cases, vomiting in eight, headache-often severe-in seven, pain in the chest in seven, and generalized pains in trunk and limbs in four. Cough was recorded in only four cases and breathlessness in two. Two patients became confused, one felt dizzy, and one was comatose for 12 hours. Lung consolidation was equally frequent on each side, and often lobar in distribution: it was generally of limited extent, but involved more than one lobe in six cases and was diffuse or patchy in two. The basal lobes were usually affected (18 of 25 consolidated lobes): the degree of illness was classified as severe in 5, moderate in 16, and slight in 4 . White blood counts were usually within normal limits, in one case low $(4,000 / \mathrm{c} . \mathrm{mm}$.), in six cases raised $(13,000$ to 28,000$)$.

Information about antibiotic therapy was available in 19 cases. Penicillin was used in 12 : satisfactory improvement followed in seven, but recovery was slow in one. Four of these patients were given a second antibiotic: satisfactory response followed administration of chloramphenicol to one ; one improved slowly on tetracycline; one responded slowly after consecutive courses of tetracycline, penicillin plus streptomycin, and finally demethylchlortetracycline ("ledermycin"); and one remained febrile after a course of chloramphenicol. This last case (Case C) was that of an alcoholic prostitute aged 48 with persistent pneumonia, aortic incompetence, peripheral neuritis, anaemia, and possible hepatic cirrhosis, who 
eventually died. Her psittacosis-group C.F. antibody titres were 512 and 1,024 in consecutive blood samples; negative reactions were obtained with antigens of influenza types A, B, and C, adenovirus, and $C$. burnetii. Although she might have been exposed to L.G.V. infection, specific features of this disease were absent. Other patients recovered satisfactorily after receiving single courses of chlortetracycline (2), chloramphenicol (2), tetracycline (2), or oxytetracycline (1).

\section{Non-specific Fever}

It is possible that most of these five patients had pulmonary infection, but none had definite clinical or radiological evidence of pneumonia. Symptoms resembled those in the pneumonia group : the onset of illness was sudden in two, with febrile "influenzal" symptoms in three, headache in three, vomiting in two, muscle pains in one, cough in one, and dyspnoea in one.

A boy with " influenzal " symptoms responded to chlortetracycline therapy. His C.F. titre fell from 400 on admission to 200. A man (Case D) with similar illness improved slowly after receiving penicillin but had two recurrences of fever and headache; after chloramphenicol treatment he recovered. His C.F. antibody titre rose from 128 to 1,024 . The other three cases were seen late in the course of illness and required no treatment. One (Case E) was the associate of one of the pneumonia patients who kept in Glasgow a flock of pigeons which sickened (Grant, 1960). His illness was characterized by malaise, headache, and very painful muscles for five weeks. $X$ ray examination showed "bronchitis"; C.F. antibody titres were 512 in each of two specimens. Another was the 72-yearold mother (Case F) of one of the pneumonia patients, both home contacts of a sick budgerigar which died : her symptoms were similar to those of her 34-year-old son (Case G), but she was not admitted to hospital. Her C.F. antibody titre was 256 in a single late specimen of serum. A 38-year-old woman on a visit from America had been febrile for two months : she recovered without treatment, and her C.F. antibody titre fell from 64 to 16 .

\section{Other Conditions}

A 10-year-old boy and a 39-year-old man both had "iniuenzal " fevers with upper respiratory symptoms. The boy had conjunctivitis, rhinitis, tonsillitis, and bronchitis, and his C.F. antibody titre rose from $<8$ to 256 . The man had pharyngitis and antibody titres of $\geqslant 512$ in each of two blood samples. Titres of 128 and 256 were found in paired sera from a 72 year-old woman who kept budgerigars; she was well, apart from chronic bronchitis. Two women in this group had cardiac disease. One, aged 75 (Case $\mathrm{H}$ ), died with bronchitis and heart failure: her antibodies, tested in 1950, increased from $<8$ to 20 . The other, aged 62 (Case I), had an " influenzal " illness which failed to respond to sulphonamide; she was admitted to hospital with signs of infective endocarditis and died with heart failure. Necropsy showed aortic stenosis and incompetence, with large vegetations, mitral stenosis, and pulmonary oedema. Repeated blood cultures were bacteriologically negative; a single serum specimen gave a C.F. titre of 128 with psittacosis-group antigen. Finally, a man aged 52 (Case $\mathrm{J}$ ) had intermittent fever and enlarged liver and spleen, without obvious cause. His psittacosis-group C.F. antibody titres were 1,024 in two specimens : serological reactions were negative $(<16)$ with $C$. burnetii and influenza $B$ and $C$ antigens, and insignificant with influenza $A$ (16) and adenovirus (32). Necropsy revealed a large mass of abdominal glands and splenomegaly. Microscopical examination of frozen sections suggested a diagnosis of lymphosarcoma, but no other tests were carried out.

\section{Epidemiological Investigations}

The diverse sources of the cases limited the extent to which personal inquiries could be made, but in most instances reasonably detailed information was received from the clinicians and public health officers concerned. Nine patients (six with pneumonia) had contact with budgerigars. In two incidents the birds had sickened and died. One bird had been sick for 10 weeks after purchase, and died on the day of admission of Case $G$ to hospital with pneumonia. This man's antibody titres rose from $<8$ to 256 . His aged mother (Case F) was also ill and had antibody in significant titre. The dead bird was not available for examination, but a more recently purchased and healthy budgerigar was found to be sero-negative. A severe case of pneumonia with antibody titres rising from 16 to $\geqslant 512$ was admitted shortly after the death of a budgerigar received as a gift : the bird had been "friendly"that is, weak and apathetic-and permitted itself to be fondled and held close to the face. Its feathers were ruffled and terminal diarrhoea preceded its death. It was not available for testing, but the history of illness was typical of psittacosis. Negative results were obtained in tests of six budgerigar contacts of unconfirmed suspects. Psittacosis virus was isolated from two budgerigars from a sick Lanarkshire flock, unassociated with recognized human illness.

Seven patients (five with pneumonia) had contact with pigeons. In three cases contact was slight and of doubtful relevance, but was considered causal in three instances. One was the episode in which two partners owning a pigeon loft in Govan became ill, one with pneumonia and the other (Case E) with fever and myalgia. As described by Grant (1960), there was sickness and mortality among the pigeons ; ornithosis virus was isolated from the pooled spleens of four birds, and serological evidence of infection was found in 9 of 16 birds tested. Management of sick birds had included feeding some of them from their owners' mouths, a procedure involving a high risk of transfer of infection. A railway guard with pneumonia and antibody titres of 256 in three blood sera had travelled periodically with consignments of racing pigeons in his van, and did so on a "pigeon special" shortly before his illness. A man severely ill with pneumonia, vomiting, and mental confusion, whose antibody titres were $\geqslant 512$ in both of two sera, had built a pigeon-house, which he entered from time to time in order to inspect the birds. None of his birds were available for examination.

It may be noted that of 14 racing-pigeon fanciers tested in 1951 only one had C.F. antibody, and this was at the insignificant titre of 8 . In addition to tests of the sick flock in Govan, the following investigations of pigeons were made. In 1959, 17 birds were examined, eight from near a Clydeside granary, eight from central Glasgow, and one from Govan Town Hall. Serological tests were made in nine, and were positive in three Glasgow birds, from one of which ornithosis virus was isolated. Isolation tests were negative in 13 birds, and the infection rate found by the combined methods was thus $3(18 \%)$ out of 17 in 1959 . Negative results were obtained in 1960 in two bird-contacts of a suspected but unconfirmed case, in two birds caught in central Glasgow in 1962 , and in one injured pigeon in Ruchill in 1963. Serological tests of 25 other Glasgow birds collected during pestcontrol operations in 1963 gave positive results in 14-an infection rate of $54 \%$.

One patient (Case D), with non-specific febrile illness and antibody titres of 128, 1,024, and 64 in consecutive blood sera, had been bitten on the finger by an elderly parrot in a public bar two months before his illness. This contact was judged to be irrelevant because of the long incubation period; in any case the parrot had continued in good health, and no virus was isolated from its droppings and mouth-swab. A man with pneumonia and antibody titres of 64 and 128 in consecutive sera had a sick canary at home. This bird was negative 
in serological tests, and no virus was isolated from its viscera. The pneumonia patient (Case A) with serological evidence of concurrent infection with both psittacosis and $Q$ fever was an electrician who had recently started work at an abattoir. No special investigations were made, but his employment obviously provided opportunities for exposure to both infections, since $Q$ fever is endemic in sheep and cattle, and the abattoir is also visited by numerous seagulls and other birds. Only two gulls, both injured, have been investigated, with negative results in each case. Negative results were also found in 13 starlings, 12 of them from central Glasgow in 1959, and one a moribund bird from Glasgow in 1963. Serological evidence of infection of cattle by an agent of the psittacosis group was also found in tests of sera collected at this laboratory for a survey of louping-ill (C. Cornwell, unpublished data). Two patients had multiple contacts of uncertain significance : one kept budgerigars in a house with numerous pigeons in the area, and also had a liking for raw eggs. Another had a pet hamster, a dog, and often fed pigeons in the park. Infection was of venereal origin in the 10 cases of L.G.V., but inquiry failed to trace the source of infection in the remaining 16 cases.

\section{Discussion}

Despite the group-reactive character of the serological test used in this study, its interpretation is clear in most cases. Association of significant titres with typical venereal disease indicates L.G.V., whereas pneumonia suggests psittacosis (acquired from psittacine birds-for example, parrots, budgerigars) or ornithosis (an almost synonymous term including infections of other birds). In the presence of other types of disease, specific interpretation of sero-positive reactions is difficult unless the epidemiological history is helpful. By absorption of sera with group antigen before using fresh unheated virus as antigen in C.F. tests, virus-specific reactions can be obtained (Bedson et al., 1949), but this procedure is technically too difficult for routine use. The superficial ocular infections (trachoma, inclusion conjunctivitis) usually fail to evoke diagnostically significant antibody response to the group antigen, though recently specific C.F. reactions have been reported using elementary-body preparations of trachoma virus (Woolridge et al., 1960).

The C.F. test with group-specific antigen provides a simple, sensitive, and rapid test for L.G.V., more satisfactory than the Frei test (Macrae, 1951). Although L.G.V. is apparently not common in the West of Scotland, the 10 cases reported here probably represent only a small proportion of the infections which occurred. The diagnostic value of the C.F. test should be remembered in cases of genito-anorectal syndrome with chronic inflammation and granulomatous, fibrotic, or fistulous lesions.

The cases of pneumonia and non-specific fever illustrate the range of clinical disease recognized in association with psittacosis. An unusual feature was the frequently lobar distribution of lung consolidation. Perhaps because of antibiotic therapy and because none of the cases were infected with the more virulent type of virus carried by parrots, the most severe forms of illness with typhoid state were not seen. Several severe cases, some with cerebral disturbance, were nevertheless encountered, and the illness of ten cleared up slowly or relapsed. Psittacosis-group organisms are less sensitive to penicillin than to broad-spectrum antibiotics, and, as shown by several cases in this series, penicillin is unreliable in treatment. Even tetracyclines, the drugs of choice, should be given in full dosage to reduce the tendency to relapse, and continued as a full course even when clinical response is rapid. Repeated courses of treatment may be necessary to eradicate infection (French and Martin, 1957). Sulphonamide therapy is usually ineffective.

Enlargement and failure of the heart is a recognized feature of psittacosis. Cardiac disease was associated with five illnesses in the present series, but was probably not caused by psittacosis in three of them : two patients with non-fatal pneumonia were known to have previously established cardiac disease, and a third and fatal case of pneumonia (Case C) had aortic incompetence. The infection could well have caused the death of the elderly woman with bronchitis and heart failure (Case B), if her low-titred antibody response from $<8$ to 20 is accepted as significant. Interest in non-bacterial forms of infective endocarditis has been aroused by recent descriptions of rickettsial endocarditis (Robson and Shimmin, 1959 ; Evans et al., 1959), but in the absence of post-mortem, histological, or cultural studies it is impossible to know whether the psittacosis antibody in the single tested serum of the woman with fatal endocarditis (Case I) was relevant to this disease or merely residual from infection some time before her final illness.

The liver and spleen may be affected in psittacosis. In the present series nausea and vomiting were common symptoms, but liver changes were recorded in only two cases. Alcoholism provides an alternative possible cause for liver damage in Case $\mathrm{C}$ and was probably related to her neuritis. The affinity of organisms of the psittacosis group for reticulo-endothelial tissue tempts speculation as to their possible relevance to the enlargement of liver, spleen, and abdominal lymph nodes in Case $\mathrm{J}$, diagnosed as lymphosarcoma. This patient had very high and specific antibody titres, and it is unfortunate that neither detailed histological nor cultural studies were carried out.

Man is the reservoir of infection with L.G.V., trachoma, and inclusion blenorrhoea. Human infection with related viruses from other species-most commonly birds-is generally by the respiratory route, producing systemic and often pneumonic disease. In birds, infection can remain latent for long periods, and virus can be excreted in their droppings, especially at the time of breeding, when nestlings become infected. Under poor conditions and overcrowding, infection may be activated, and then virus may also be excreted in the respiratory discharges of the sick bird. This was a potent cause of human infection in the epidemic of psittacosis which followed importation of South American parrots into Britain and other countries in 1930, and more recently large outbreaks of ornithosis have been associated with intensive rearing and slaughter of poultry in Eastern Europe (Ortel, 1963). The spring rise in incidence of pneumonic infection reported in the present study might reflect either the breeding cycle of birds or perhaps the increased trade in cage-birds at Christmas.

\section{Problems of Control}

The epidemiology and problems of control of psittacosis have been reviewed by Meyer (1959). Budgerigars are the commonest household cage-birds in Britain, and several were found infected in the present study. Budgerigars were also the probable source of infection of a husband and wife with typhoid-like illness (associated with pneumonia in the wife) in Lanarkshire in 1939 (Reid, 1940). Virus can be excreted by apparently healthy birds, and those which are unusually docile may simply be too sick to protest. Overcrowding and bad management of birds before sale is conducive to activation and spread of infection among the birds. Unhygienic practices such as feeding birds from the lips encourage transfer of the virus to man.

Pigeons, wild and tame, are another well-known source of infection. Breeders, or others whose activities involve close contact with pigeons or their living quarters, are particularly at risk. Infection of a railway guard accompanying racing pigeons has been previously reported (Dew et al., 1960), and Dekking (1963) reports that racing pigeons are the most important source of human ornithosis in the Netherlands. Nevertheless, 
no serological evidence of recent infection was found in our tests of 14 pigeon fanciers in 1951.

Hens, ducks, and turkeys were not incriminated in the present study, although they have caused outbreaks in other countries (Meyer, 1959 ; Ortel, 1963). Other domestic animals have not been recognized in Britain as important causes of human infection with organisms of the psittacosis group, although Barwell (1955) reported that the virus of enzootic abortion of ewes can infect man. Human infections with closely related agents arising from close association with cattle in tropical Africa were reported by Giroud and Jadin (1954). In many of their cases the lungs were not obviously involved: neurological and abdominal symptoms were common, with skin rash in some cases. The considerable enlargement of mesenteric lymph nodes in several fatal African cases is interesting in view of the intra-abdominal masses of lymphosarcomatous appearance in Case J. Subsequent investigations revealed the same type of infection in North Africa and in Metropolitan France, sometimes in human cases of abortion (Lefebre, 1962).

In seeking to explain our 16 cases whose sources of infection could not be traced, one may postulate the rare chance of inhalation of an infected particle discharged by a passing bird. Despite the heavy soiling of many cities by the droppings of pigeons and starlings, it is unlikely that the labile ornithosis viruses remain viable for more than a short time in such material. The small number of cases in our 14-year study which might have originated thus shows that this risk is very slight. Another possibility is that infections were acquired from mammals, and it should be remembered that not only large domestic animals but also cats, dogs, and mice may harbour organisms of the psittacosis-L.G.V. group. However, effective transmission of infection to man would probably require close contact between man and animals, as in most of the cases studied by Giroud and Jadin (1954).

It appears impracticable to attempt eradication of organisms of the psittacosis-L.G.V. group which are widely distributed as infections of innumerable species of birds and mammals. Apart from chemotherapy and perhaps vaccines against those whose normal host is man, the prevention of human infection depends essentially on avoidance of close contact between man and birds (and sometimes other animals), particularly in closed spaces such as the household room or pigeon-loft. High standards of hygiene are necessary for aviaries and poultrypacking stations and during the transport and holding of pet birds by dealers. Although the dense populations of pigeons and starlings in many of our cities may be undesirable on other grounds, our investigations in Glasgow have provided no evidence that they have caused an important number of serious ornithosis infections of man in recent years.

\section{Summary}

In the period 1950-63, a serological diagnosis of infection with virus of the psittacosis-L.G.V. group was made in 45 cases, classified as pneumonia (24), lymphogranuloma venereum (10), non-specific fever (5), and other conditions (6). The patients' ages ranged from 6 to 75 years. Their illnesses occurred at all seasons, with increased prevalence of pneumonia in the first quarter of the year. The possible role of infection in two cases of cardiac disease and two cases of liver disease (one with apparent lymphosarcoma) is discussed.

Several patients had been in contact with pigeons or budgerigars, and infection was demonstrated in birds of both species. In $196354 \%$ of Glasgow pigeons were found to be infected but did not appear to have caused an important amount of human disease. The possible acquisition of human infections from other animals is considered.

Penicillin therapy was often inadequate and treatment with full dosage of tetracyclines is recommended, perhaps with repeated courses to eradicate infection.

Technical assistance during this investigation was given by the late Mr. G. Rowan, A.I.M.L.T., and by Miss R. McLelland, F.A.T.A., Mrs. C. Rutter, Mr. H. G. Carson, F.I.M.L.T., and Mr. S. McMichael, A.I.M.L.T. We gratefully acknowledge the co-operation of our colleagues in the wards and laboratories of Belvidere, Knightswood, Ruchill, and Southern General Hospitals, and the Royal, Victoria, and Western Infirmaries of Glasgow, Ayrshire Central Hospital, Bridge of Earn Hospital, Gateside Hospital, Greenock, and Stirling Royal Infirmary; also of Dr. K. Foulis, general practitioner. We also thank the Medical Officers of Health of Glasgow, Greenock, Motherwell, Lanark County, Paisley, Port Glasgow, and Renfrewshire, and members of their staffs, and Mr. W. Grant, of the Animal Health Branch of the Ministry of Agriculture, Fisheries, and Food, for help in the epidemiological investigations.

\section{REFERENCBS}

Allison, A., and Dick, A. (1954). Lancet, 2, 364.

Barwell, C. F. (1955). Ibid., 2, 1369.

Bedson, S. P., Barwell, C. F., King, E. J., and Bishop, L. W. J. (1949). f. clin. Path., 2, 241.

Dekking, F. (1963). Arch. ges. Virusforsch., 13, 316.

Dew, J., Mawson, K., Ellman, P., and Brough, D. (1960). Lancet, 2,

Evans, A. D., Powell, D. E. B., and Burrell, C. D. (1959). Ibid., 1, 864.

French, E. L., and Martin, F. I. R. (1957). Ibid., 2, 1321.

Giroud, P., and Jadin, J. (1954). Bull. Soc. Path. exot., 47, 578.

Grant, W. (1960). State Vet. F., 15, 70.

Grist, N. R. (1954). Lancet, 1, 650.

Karrer, H., Meyer, K. F., and Eddie, B. (1950). F. infect. Dis., 87, 13. Lefebre, M. G. (1962). M.D. Thesis, Faculty of Medicine, Paris.

Macrae, A. D. (1951). Brit. F. vener. Dis., 27, 183.

Meyer, K. F. (1959). Bull. Wld Hlth Org., 20, 101.

and Eddie, B. (1951). F. infect. Dis., 88, 109.

Ortel, S. (1963). Münch. med. W schr., 105, 1105.

Reid, J. (1940). Annuad Report by the Physician-Superintendent, County of Lanark Infectious Diseases Hospital, 1939. Anderson, Glasgow.

Robson, A. O., and Shimmin, C. D. G. L. (1959). Brit. med. F., 2, 980.

Stamp, J. T., McEwen, A. D., Watt, J. A. A., and Nisbet, D. I. (1950). Vet. Rec., 62, 251.

Woolridge, R. L., Jackson, E. R., and Grayston, J. T. (1960). Proc. Soc. exp. Biol. (N.Y.), 104, 298 . 